\title{
Analisa Tingkat Kematangan Teknologi Informasi Domain Acquire \& Implement : Studi Kasus Universitas Pembangunan Jaya
}

\author{
Denny Ganjar Purnama \\ Program Studi Sistem Informasi, Universitas Pembangunan Jaya \\ denny.ganjar@upj.ac.id
}

\begin{abstract}
Optimal utilization of Information Technology (IT) is felt to be increasingly important in an effort to achieve maximum levels of performance. To improve performance, good IT planning and governance is needed. The implementation of ad-hoc IT activities will cause waste. This descriptive study aims to get an idea of how the conditions of governance in the process of IT activities at Pembangunan Jaya University are used as case study sites. Evaluation and analysis is carried out for analysis and knowing the acquisition and implementation of IT used. Evaluation and analysis using the COBIT 4.1 framework. The domains used are Acquire \& Implement (AI), because this domain includes the acquisition and implementation of IT including management of changes. The purpose of this study is to evaluate and make the results of the analysis as input to improve the management of IT running at the institution.
\end{abstract}

Keywords : IT Governance, COBIT 4.1, Acquire \& Implement

\begin{abstract}
Abstrak : Pemanfaatan Teknologi Informasi (TI) yang optimal sangat penting dalam upaya mencapai tingkat kinerja yang maksimal. Untuk meningkatkan kinerja, diperlukan perencanaan pemerolehan atau penerapan layanan TI yang baik. Tingkat pemerolehan dan penerapan layanan TI yang bersifat ad-hoc dan memiliki celah yang cukup besar dengan expected level pada best practice COBIT 4.1 hanya akan menyebabkan terjadinya pemborosan semata. Penelitian yang bersifat deskriptif ini bertujuan untuk mendapatkan gambaran bagaimana kondisi tata kelola pada proses kegiatan TI di Universitas Pembangunan Jaya yang dijadikan sebagai tempat studi kasus. Evaluasi dan analisa dilakukan untuk menganalisis dan mengetahui pemerolehan dan penerapan TI yang digunakan. Evaluasi dan analisa menggunakan framework COBIT 4.1. Domain yang digunakan adalah Acquire \& Implement (AI), karena domain ini mengelola pemerolehan dan penerapan TI termasuk pengelolaan perubahannya. Tujuan dari penelitian ini adalah untuk mengevaluasi dan menjadikan hasil analisa sebagai masukan untuk memperbaiki pengelolaan TI yang berjalan pada institusi tersebut.
\end{abstract}

Kata Kunci : Tata Kelola TI, COBIT 4.1, Acquire \& Implement

\section{PENDAHULUAN}

Teknologi informasi di Universitas Pembangunan Jaya saat ini memiliki peran yang sangat penting, khususnya sebagai pendukung utama fungsi operasional yang strategis. Penerapan sistem informasi pun dilakukan secara luas dan komprehensif. Dengan diterapkannya sistem informasi pada kegiatan operasional tentunya akan sangat membantu, namun disamping itu juga perlu disadari bahwa sistem informasi ini juga harus dievaluasi untuk mengetahui sampai mana sistem telah memenuhi kebutuhan universitas lalu dilakukan pengembangan sistem yang lebih baik agar hasil yang optimal dapat diperoleh. Oleh karena itu, perlu dilakukan pengukuran tingkat kematangan sistem informasi secara berkala.

\section{Formulasi Masalah}

Perubahan adalah sesuatu yang alami, walaupun tetap harus disikapi secara tepat dan terstruktur, sehingga berdasarkan latar belakang yang telah diuraikan sebelumnya, permasalahan utama yang akan diteliti adalah seberapa besar celah (gap) antara tingkat kematangan tata kelola TI Domain Acquire \& Implement di Universitas Pembangunan Jaya saat ini, dengan best practice CobiT 4.1.

\section{Tujuan}

Adapun tujuan penelitian ini dilakukan adalah :

1. Mengetahui kondisi penerapan tata kelola TI Domain Acquire \& Implement yang berjalan di UPJ. 
2. Mengetahui tingkat kematangan (Maturity Level) dari Domain Acquire \& Implement di UPJ dengan menggunakan kerangka kerja utama CobiT 4.1.

\section{COBIT 4.1}

\section{CobiT (Control Objective for} Information and Related Technology) merupakan suatu standar atau kerangka kerja yang diterbitkan oleh ISACA untuk audit Teknologi Informasi. CobiT dikenal juga sebagai best practice dalam membangun kerangka kerja kontrol dan IT audit baik diadopsi sebagian maupun seluruhnya. CobiT versi terbaru adalah CobiT versi 5.0, namun untuk penelitian ini masih menggunakan CobiT versi sebelumnya, yaitu CobiT 4.1.

Secara umum kerangka kerja CobiT dipetakan ke dalam management cycles dan memiliki 4 domain yang diarahkan untuk :

Plan \& Organize (PO) - terkait dengan identifikasi TI yang bisa memberikan kontribusi pada pencapaian tujuan bisnis. Domain ini menjawab pertanyaan sebagai berikut :

a. Apakah strategi TI selaras dengan strategi bisnis ?

b. Apakah organisasi telah melakukan penggunaan sumber daya secara optimal ?

c. Apakah setiap orang di dalam organisasi mengerti tujuan TI ?

d. Apakah resiko TI dimengerti dan dapat dikelola dengan baik ?

e. Apakah kualitas dari sistem TI sejalan dengan kebutuhan bisnis ?

Acquire and Implement (AI) - terkait dengan bagaimana memperoleh, menerapkan atau mengembangan solusi TI yang dapat diintegrasikan ke dalam proses bisnis. Perubahan dan perawatan sistem juga merupakan cakupan dari domain ini untuk memastikan solusi TI dapat memenuhi tujuan bisnis. Domain ini menjawab pertanyaan sebagai berikut : f. Apakah project yang baru dapat memberikan solusi yang diperlukan dalam kebutuhan bisnis ?

g. Apakah project yang baru dapat diselesaikan tepat waktu dan sesuai dengan anggaran ?

h. Apakah sistem yang baru akan bekerja dengan baik pada saat diimplementasikan?

i. Apakah perubahan yang terjadi tidak mengganggu operasi bisnis saat ini ?

Delivery \& Support (DS) - terkait dengan penyerahan jasa yang dibutuhkan termasuk operasional, keamanan, dan pelatihan. Sehingga domain ini berhubungan dengan realisasi pelayanan yang dibutuhkan, dimana didalamnya termasuk pemberian layanan serta keberlanjutan dukungan layanan untuk pengguna. Domain ini dapat menjawab beberapa pertanyaan sebagai berikut :

j. Apakah layanan TI ini diimplementasikan sesuai dengan prioritas bisnis ?

k. Apakah biaya TI sudah optimal ?

1. Apakah para individu dapat menggunakan Sistem TI secara produktif dan aman?

m. Apakah tingkat kerahasiaan, integritas dan ketersediaan cukup untuk mendukung keamanan informasi ?

Monitor \& Evaluate (ME) - terkait dengan penilaian rutin dari waktu ke waktu agar kualitas dan kesesuaian dengan persyaratan selalu terkontrol, termasuk pengaturan untuk kerja, monitoring kendali internal dan ketaatan terhadap peraturan yang berlaku. Domain ini dapat menjawab beberapa pertanyaan berikut :

n. Apakah pengukuran performa TI dapat mendeteksi masalah sebelum terlambat?

o. Apakah manajemen dapat memastikan kontrol internal berjalan efektif dan efisien? 
p. Apakah performa TI dapat dihubungkan kembali dengan tujuan bisnis ?

q. Apakah pengendalian kerahasiaan, integritas dan ketersediaan sudah memadai untuk mendukung keamanan informasi ?

Dan dari ke-empat domain tersebut di atas, diturunkan menjadi 34 proses kerja atau yang disebut dalam CobiT 4.1 adalah High Level Control Objectives yang dapat dilihat pada tabel berikut :

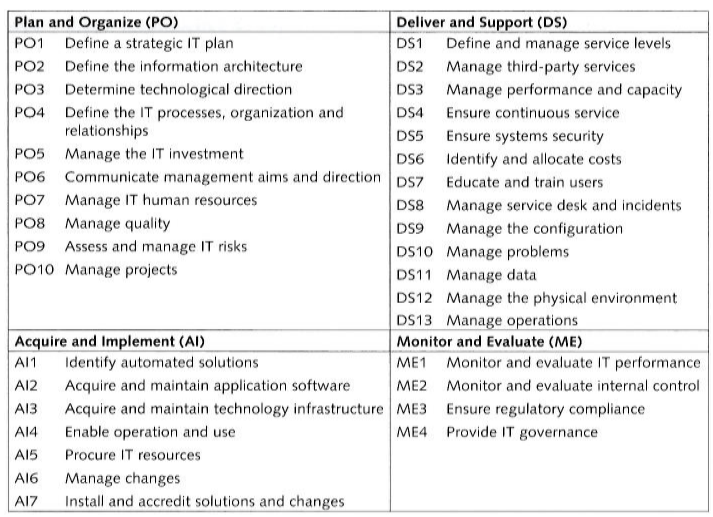

Gambar 1. 34 Proses Kerja CobiT 4.1

Pada penelitian ini, penulis akan fokus untuk menitikberatkan pada proses kerja yang terkait dengan domain acquire \& implement, hal ini diyakini agar dapat menjawab pertanyaan penelitian dan permasalahan yang dihadapi oleh Universitas Pembangunan Jaya secara efektif. Adapun gambaran kerangka kerja CobiT 4.1 secara lengkapnya dapat disampaikan pada Gambar 2.

Selain itu, di dalam kerangka kerja CobiT 4.1 terdapat bahasan mengenai maturity level yang merupakan alat bantu bagi pihak pengelola untuk melakukan self assessment pengelolaan TI yang diterapkan. Maturity model dapat digunakan untuk memetakan :

1. Status pengelolaan TI perusahaan pada saat itu.

2. Status standar industri dalam bidang TI saat ini (sebagai pembanding)

3. Status standar internasional dalam bidang TI saat ini (sebagai pembanding)
4. Strategi pengelolaan TI perusahaan (ekspektasi perusahaan terhadap posisi pengelolaan TI perusahaan)

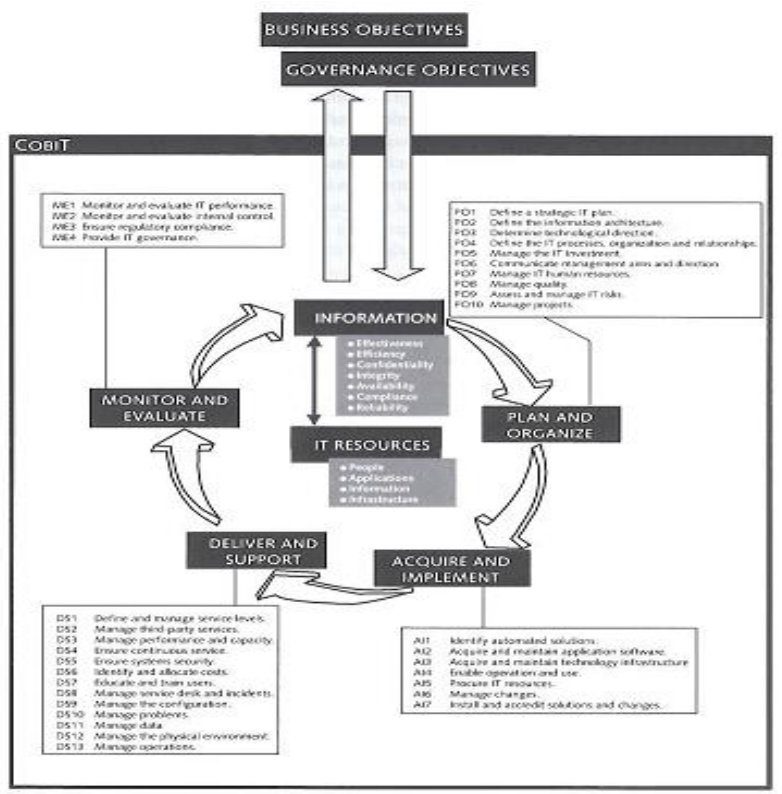

Gambar 2. Framework CobiT 4.1

Adapun di dalam hasil penilaian assessment, tingkat kematangan pengelolaan TI dapat dibagi menjadi 6 level sebagai berikut :

- Level 0 (Non - existent) ; perusahaan tidak mengetahui sama sekali proses teknologi informasi di perusahaannya atau belum pernah dilakukan dalam perusahaan.

- Level 1 (Initial Level); perusahaan telah mengetahui masalah yang perlu ditangani tetapi tidak ada standar dan cenderung diperlakukan secara ad hoc.

- Level 2 (Repeatable Level) ; pada level ini, perusahaan sudah melakukan proses ini namun tidak ada dokumentasi.

- Level 3 (Defined Level) ; pada level ini, proses sudah didokumentasikan dan telah memiliki standar.

- Level 4 (Managed Level) ; pada level ini, perusahaan sudah membuat suatu matrik untuk suatu produk, proses dan pengukuran hasil. Proses pengembangan dapat ditentukan karena proses telah diukur dan dijalankan dengan batas yang dapat diukur. 
- Level 5 (Optimized Level) ; pada level ini, perusahaan telah fokus pada proses peningkatan secara terus menerus. Teknologi informasi sudah digunakan terintegrasi untuk otomatisasi proses kerja dalam perusahaan untuk meningkatkan kualitas, efektifitas, serta kemampuan beradaptasi perusahaan.

\section{METODA \& TAHAPAN PENELITIAN}

Penelitian ini menggunakan metoda penelitian studi evaluasi dan analisa dengan data kualitatif (qualitative research), dengan menggunakan studi kasus yang terjadi pada Universitas Pembangunan Jaya.

Adapun pada saat melakukan penelitian ini, penulis mempergunakan tahapan penelitian sebagai berikut :

- Melakukan studi literatur dengan mengumpulkan beberapa teori atau kerangka kerja yang umum digunakan pada penerapan IT Governance yang dibutuhkan dalam penelitian;

- Melakukan penelitian lapangan dengan pendekatan observasi secara langsung, penelitian dan penelaahan dokumendokumen terkait serta melakukan wawancara / kuisioner untuk memvalidasi hasil pengamatan yang diperoleh;

- Melakukan penulisan laporan deskriptif dari hasil penelitian studi kasus pemetaan IT Governance di Universitas Pembangunan Jaya.

Terdapat dua jenis metoda pengumpulan data yang akan dilakukan dalam penelitian ini, yaitu :

- Pengumpulan data primer yang diambil langsung dengan melakukan wawancara / kuisioner dan survei lapangan terhadap perwakilan dari pihak manajemen TI Universitas Pembangunan Jaya yang berkaitan dengan penelitian.

- Pengumpulan data sekunder yang diambil dari dokumen-dokumen institusi yang terkait dengan penelitian.

Detil tahapan penelitian sebagaimana yang digambarkan pada Gambar 3, dapat diperhatikan bahwa penelitian ini dimulai dengan melakukan perumusan masalah penelitian, yang akan menghasilkan pertanyaan penelitian (research question), setelah itu penulis akan melakukan studi literatur, antara lain dengan meneliti referensi maupun bukubuku terkait dengan tata kelola TI. Setelah permasalahan penelitian dirumuskan, penulis akan memfokuskan pada perancangan format wawancara / kuisioner, hal ini sangat penting dilakukan agar hasil data wawancara/kuisioner dapat lebih fokus dan dapat dimanfaatkan sepenuhnya untuk memecahkan permasalahan penelitian yang sebenarnya.

Dengan format wawancara/ kuisioner yang telah dirancang, penulis telah dapat memulai mengumpulkan data dari obyek penelitian, antara lain data tertulis maupun data yang berasal dari wawancara / kuisioner. Dari hasil wawancara / kuisioner dan informasi lainnya tersebut, penulis dapat memetakan pola tata kelola TI saat ini yang diterapkan oleh UPJ, yang kemudian dapat dilakukan pengukuran tingkat kematangannya.

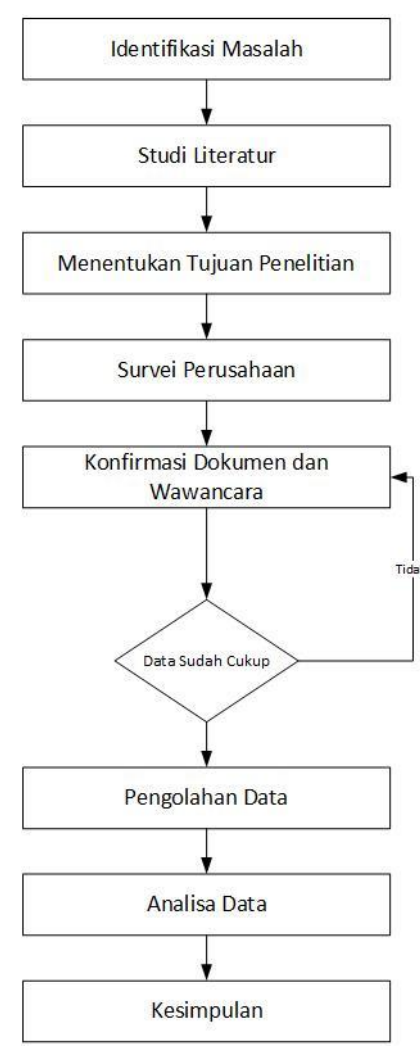

Gambar 3. Diagram Tahapan Penelitian 


\section{HASIL PENELITIAN DAN ANALISIS}

Lingkup pengumpulan data yang dilakukan pada UPJ meliputi proses-proses yang terkandung pada domain Acquire \& Implement, sebagai berikut :

\section{A. AI1 Identify Automated Solutions / Identifikasi Solusi Otomatis}

Kebutuhan akan aplikasi baru memerlukan analisis sebelum akuisisi atau pembuatannya untuk memastikan bahwa persyaratan bisnis dipenuhi dengan pendekatan yang efektif dan efisien. Proses ini mencakup definisi kebutuhan, pertimbangan sumber alternatif, tinjauan kelayakan teknologi dan ekonomi, pelaksanaan analisis risiko dan analisis biaya-manfaat, dan kesimpulan final keputusan untuk 'membuat' atau 'membeli'. Semua langkah ini memungkinkan organisasi untuk meminimalkan biaya untuk memperoleh dan mengimplementasi kan suatu solusi.

Tabel 1. Hasil Evaluasi AI1

Hasil Evaluasi AI1 Identify Automated Solutions / Identifikasi Solusi Otomatis UPJ telah memiliki pendekatan yang terstruktur dalam menentukan solusi TI, proses untuk menentukan solusi TI diterapkan untuk beberapa proyek berdasarkan faktor-faktor seperti keputusan yang dibuat oleh anggota staf individu yang terlibat.

Current Maturity $\quad 3,22$

Expected Maturity $\quad 4,00$

Domain ini terbagi menjadi 4 sub-domain antara lain :

1. AI1.1 Definition and Maintenance of Business Functional and Technical Requirements

2. AI1.2 Risk Analysis Report

3. AI1.3 Feasibility Study and Formulation of Alternative Courses of Action

4. AI1.4 Requirements and Feasibility Decision and Approval

\section{B. AI2 Acquire and Maintain Application Software / Memperoleh dan Memelihara Aplikasi Perangkat Lunak}

Penyediaan aplikasi harus sesuai dengan persyaratan bisnis. Proses ini mencakup desain aplikasi yang tepat dengan penyertaan kontrol aplikasi dan persyaratan keamanan, dan pengembangan serta konfigurasi sesuai dengan standar. Hal ini memungkinkan organisasi untuk mendukung operasi bisnis yang benar dengan aplikasi otomatis yang benar. Domain ini terbagi menjadi 10 sub-domain antara lain :

1. AI2.1 High-level Design

2. AI2.2 Detailed Design

3. AI2.3 Application Control and Auditability

4. AI2.4 Application Security and Availability

5. AI2.5 Configuration and Implementation of Acquired Application Software

6. AI2.6 Major Upgrades to Existing Systems

7. AI2.7 Development of Application Software

8. AI2.8 Software Quality Assurance

9. AI2.9 Applications Requirements Management

10. AI2.10 Application Software Maintenance

Tabel 2. Hasil Evaluasi AI2

Hasil Evaluasi AI2 Acquire and Maintain Application Software / Memperoleh dan Memelihara Aplikasi Perangkat Lunak

UPJ telah menerapkan proses ini sejalan dengan IT dan strategi bisnis, dengan sedikit pertimbangan keamanan dan ketersediaan aplikasi dalam desain atau akuisisi perangkat lunak aplikasi

Current Maturity $\quad 3,14$

Expected Maturity $\quad 4,00$ 


\section{AI3 Acquire and Maintain Technology Infrastructure / Memperoleh dan Memelihara Infrastruktur Teknologi}

Institusi memiliki proses untuk akuisisi, implementasi, dan peningkatan infrastruktur teknologi. Proses ini membutuhkan pendekatan yang direncanakan untuk akuisisi, pemeliharaan dan perlindungan infrastruktur sejalan dengan strategi teknologi yang disepakati. Proses ini memastikan bahwa ada dukungan teknologi yang berkelanjutan untuk aplikasi bisnis. Domain ini terbagi menjadi 4 sub-domain antara lain :

1. AI3.1 Technological Infrastructure Acquisition Plan

2. AI3.2 Infrastructure Resource Protection and Availability

3. AI3.3 Infrastructure Maintenance

4. AI3.4 Feasibility Test Environment

Tabel 3. Hasil Evaluasi AI3

Hasil Evaluasi AI3 Acquire and Maintain Technology Infrastructure / Memperoleh dan Memelihara Infrastruktur Teknologi UPJ telah menerapkan proses ini untuk mendukung kebutuhan aplikasi bisnis kritis dan sejalan dengan strategi bisnis, sudah diterapkan secara konsisten, memiliki lingkungan yang terpisah untuk pengembangan dan produksi.

$\begin{array}{ll}\text { Current Maturity } & 3,72 \\ \text { Expected Maturity } & 4,00\end{array}$

\section{AI4 Enable Operation and Use /} Aktifkan Operasi dan Penggunaan

Pengetahuan tentang sistem baru harus tersedia setiap saat. Proses ini membutuhkan penyediaan dokumentasi dan petunjuk manual bagi pengguna dan administrator TI, serta wajib menyediakan pelatihan untuk memastikan penggunaan atau pengoperasian aplikasi dan pemeliharaan infrastruktur yang tepat. Domain ini terbagi menjadi 4 sub-domain antara lain :

1. AI4.1 Planning for Operational Solutions

2. AI4.2 Knowledge Transfer to Business Management
3. AI4.3 Knowledge Transfer to End Users

4. AI4.4 Knowledge Transfer to Operations and Support Staff

Tabel 4. Hasil Evaluasi AI4

Hasil Evaluasi AI4 Enable Operation and Use / Aktifkan Operasi dan Penggunaan

UPJ telah memiliki kerangka kerja untuk menyusun prosedur dan materi pelatihan. Pendekatan yang dilakukan untuk menjaga prosedur dan manual pelatihan mencakup semua sistem dan unit bisnis, sehingga proses dapat dilihat dari perspektif bisnis. Prosedur dan materi pelatihan sudah terintegrasi. Terdapat kontrol untuk menjamin kepatuhan terhadap standar, dan prosedur yang dikembangkan. Bisnis dan pengguna belum memberikan umpan balik atas dokumentasi dan pelatihan. Dokumentasi dan materi pelatihan sudah tersedia dalam bentuk digital.

$\begin{array}{ll}\text { Current Maturity } & 3,34 \\ \text { Expected Maturity } & 4,00\end{array}$

\section{E. AI5 Procure IT Resources / Pengadaan Sumber Daya TI}

Sumber daya TI, termasuk orang, perangkat keras, perangkat lunak, dan layanan, perlu dibeli. Hal ini membutuhkan definisi dan penegakan prosedur pengadaan, pemilihan vendor, pengaturan kontrak, dan pengadaannya itu sendiri. Proses ini memastikan bahwa organisasi memiliki semua sumber daya TI yang diperlukan secara tepat waktu dan tepat biaya. Domain ini terbagi menjadi 4 sub-domain antara lain :

1. AI5.1 Procurement Control

2. AI5.2 Supplier Contract Management

3. AI5.3 Supplier Selection

4. AI5.4 IT Resources Acquisition

Tabel 5. Hasil Evaluasi AI5 Hasil Evaluasi AI5 Procure IT Resources / Pengadaan Sumber Daya TI 
UPJ telah memiliki sistem pengadaan sumber daya TI yang sepenuhnya terintegrasi dengan sistem pengadaan bisnis secara keseluruhan. Memiliki standar TI untuk pengadaan sumber daya TI yang digunakan. Manajemen biasanya menyadari pengecualian terhadap kebijakan dan prosedur untuk pengadaan IT. Manajemen TI mengharuskan penggunaan sistem pengadaan dan proses kontrak untuk semua pengadaan TI dengan meninjau pengukuran / evaluasi kinerja.

Current Maturity $\quad 3,14$

Expected Maturity $\quad 4,00$

\section{F. AI6 Manage Changes / Mengelola Perubahan}

Semua perubahan, termasuk pemeliharaan darurat dan perbaikan, terkait dengan infrastruktur dan aplikasi dalam lingkungan live production dikelola secara formal dengan cara yang terkendali. Perubahan (termasuk yang terkait dengan prosedur, proses, sistem dan layanan parameter) dicatat, dinilai dan disahkan sebelum implementasi dan ditinjau terhadap hasil yang direncanakan berikut pelaksanaannya. Hal ini untuk memastikan mitigasi risiko terhadap stabilitas atau integritas lingkungan live production. Domain ini terbagi menjadi 5 sub-domain antara lain :

1. AI6.1 Change Standards and Procedures

2. AI6.2 Impact Assessment, Prioritisation and Authorisation

3. AI6.3 Emergency Changes

4. AI6.4 Change Status Tracking and Reporting

5. AI6.5 Change Closure and Documentation

Tabel 6. Hasil Evaluasi AI6

Hasil Evaluasi AI6 Manage Changes / Mengelola Perubahan

UPJ telah menerapkan sebuah proses perubahan formal dan perubahan yang paling mengikuti pendekatan bisnis, namun belum terstruktur dan masih sederhana. Penyimpanan dokumentasi cukup konsisten, dan sudah dilakukan perencanaan dan penilaian dampak terhadap suatu permintaan perubahan. Analisis dampak perubahan TI pada operasi bisnis belum dilakukan secara formal.

$\begin{array}{ll}\text { Current Maturity } & 3,47 \\ \text { Expected Maturity } & 4,00\end{array}$

\section{G. AI7 Install and Accredit Solutions and Changes / Instal dan Akreditasi Solusi dan Perubahan}

Sistem baru akan diluncurkan ke operasional setelah pengembangan selesai. Proses ini membutuhkan pengujian yang tepat dalam lingkungan yang khusus dengan data uji yang relevan, tahapan peluncuran dan instruksi migrasi yang jelas, perencanaan rilis ke dalam live production, serta evaluasi pasca implementasi. Semua ini untuk memastikan bahwa sistem operasional sudah sesuai dengan harapan dan hasil yang disepakati. Domain ini terbagi menjadi 9 sub-domain antara lain :

1. AI7.1 Training

2. AI7.2 Test Plan

3. AI7.3 Implementation Plan

4. AI7.4 Test Environment

5. AI7.5 System and Data Conversion

6. AI7.6 Testing of Changes

7. AI7.7 Final Acceptance Test

8. AI7.8 Promotion to Production

9. AI7.9 Post-implementation Review

Tabel 7. Hasil Evaluasi AI7 Hasil Evaluasi AI7 Install and Accredit Solutions and Changes / Instal dan Akreditasi Solusi dan Perubahan

UPJ baru menerapkan prosedur secara informal namun memiliki lingkungan tes yang jelas dan terdefinisi. Pelatihan, pengujian dan transisi ke lingkungan produksi cenderung bervariasi tergantung aplikasi yang digunakan, berdasarkan keputusan manajemen TI.

Current Maturity $\quad 2,88$

Expected Maturity $\quad 3,00$ 
Keseluruhan current maturity dan expected maturity dapat dilihat pada Gambar 4. Current Maturity vs Expected Maturity Domain Acquire \& Implement

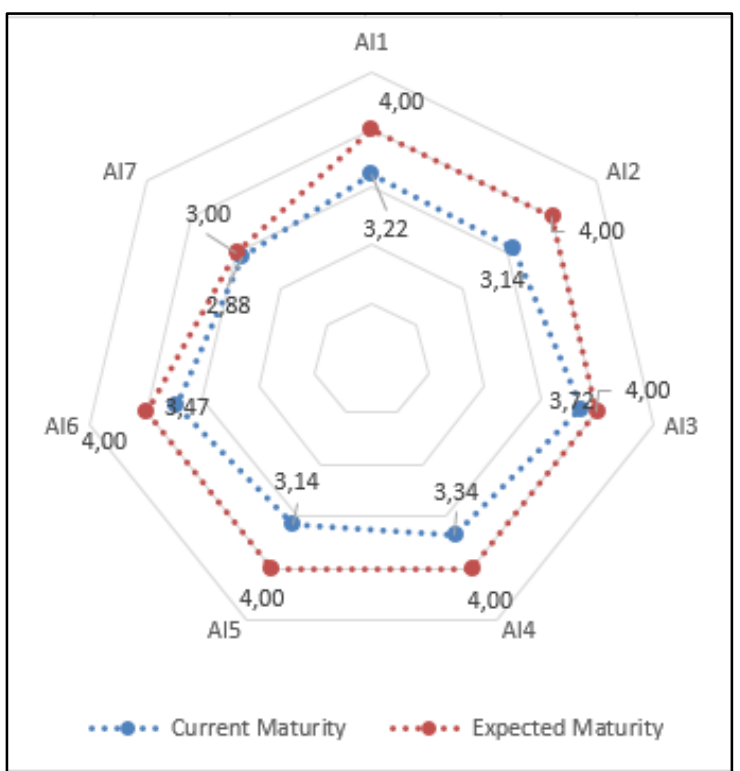

Gambar 4. Current Maturity vs Expected Maturity Domain Acquire \& Implement

\section{KESIMPULAN DAN SARAN}

Dari penelitian ini, diperoleh kesimpulan sebagai berikut :

1. Nilai current maturity level terendah berada pada proses AI7 Instal dan Akreditasi Solusi dan Perubahan dengan nilai level 2,88. Adapun expected maturity level yang diharapkan yaitu berada pada nilai level 3,00, selisih sedikit sehingga tidak sulit untuk mencapai level yang diharapkan.

2. Untuk proses AI1, AI2, AI4, AI5 walaupun sudah memiliki tingkat kematangan yang cukup tinggi, diatas level 3,00, namun memiliki selisih yang cukup lebar menuju expected maturity level yaitu level 4,00, sehingga masih banyak dibutuhkan pengembangan dan peningkatan.

3. Nilai current maturity level untuk proses AI3 dan AI6 sudah cukup tinggi dan cukup dekat dengan expected maturity level yaitu 4,00, sehingga tidak terlalu sulit untuk melakukan peningkatannya.

4. Secara keseluruhan, proses pada domain acquire \& implement di UPJ sudah berjalan dengan baik, hampir keseluruhan proses sudah diatas tingkat kematangan 3,00, namun tetap perlu dilakukan peningkatan agar lebih baik lagi ke depannya.

Berdasarkan kesimpulan diatas, dapat diberikan beberapa saran yang bisa dilakukan oleh UPJ, yaitu :

1. Perlu dilakukan percepatan pemerolehan dan penerapan layanan TI, khususnya untuk proses / sub domain yang memiliki selisih yang tidak jauh dengan expected maturity level-nya, bisa dilakukan dengan cara outsourcing ataupun kerjasama dengan institusi pendidikan tinggi lain.

2. Hendaknya perlu dibuatkan suatu prosedur tetap untuk proses peluncuran suatu aplikasi, agar proses penerapan suatu aplikasi dapat berjalan dengan lancar dan dapat digunakan dengan baik.

\section{DAFTAR PUSTAKA}

1. ITGI. "Cobit 4.1", 2007.

2. ITGI, Cobit 4.1, Executive Summary Framework, 2007.

3. ITGI, Cobit Mapping, Mapping of ITIL v3 With COBIT 4.1, 2008.

4. Weills, Peter and Ross, Jeanne W., How Top Performers Manage IT Decision Rights for Superior Results, Hardvard Business School Press, 2004.

5. Tobias Goldschmidt, Andreas Dittrich and Miroslaw Malek, Quantifying Critically of Dependability-Related IT Organization Process in Cobit, Institut fur Informatik, Humboldt-Universitat zu Berlin, Germany. 